simplest instructions. The diuretic frusemide, two $40-\mathrm{mg}$ tablets four-hourly until medical help is available, is recommended on the general grounds that a reduction in the volume of body fluid is likely to be desirable, though it is admitted that there is no direct evidence of this in the highaltitude form of pulmonary oedema. Frusemide also offers some psychological advantage, for the diuresis reassures the patient that a potent drug with an obvious effect is being given to help him.

If qualified medical help is available, it seems generally agreed that morphine as well as frusemide should be given and that it sometimes produces a dramatic improvement, ${ }^{8}$ perhaps partly because of its sedative effect and partly because of its peripheral venodilator action. ${ }^{13}$ But agreement is lacking on the use of cardiac glycosides, some authorities advocating them and some denying their value. One form of treatment which does seem to be of real help in severe cases is positive-pressure artificial ventilation, which among other things will raise the pulmonary interstitial fluid pressure.

At present the causes and mechanism of high-altitude pulmonary oedema are far from being understood, and because of the environmental conditions in which it occurs controlled trials of different forms of treatment present obvious problems. But simple education of people visiting high mountains will help to prevent it, and the provision of emergency stretchers, oxygen, and frusemide (with clear instructions on their use) in huts at high altitude will allow effectual first aid to be carried out.

1 Alzamora-Castro, V., Garrido-Lecca, G., and Battilana, G., American Fournal of Cardiology, 1962, 7, 769.

2 Fred, H. L., Schmidt, A. M., Bates, T., and Hecht, H. H., Circulation, $1962,25,929$.

3 Houston, C. S., New England Fournal of Medicine, 1960, 263, 478.

4 Hultgren, H. N., Spickard, W., Heliriegel, K., and Houston, C. S., Medicine, 1961, 40, 289.

5 Hultgren, H. N., Spickard, W., and Lopez, C., British Heart fournal,

1962, 24, 95.

Fenn and H. Rahn. Washington, American Physiological Society, 1965.

7 Singh, I., Kapila, C. C., Khanna, P. K., Nanda, R. B., and Rao, B. D. P., Lancet, 1965, 1, 229.

B Singh, I., et al., New England fournal of Medicine, 1969, 280, 175.

Boothby, W. M., Lovelace, W. R., Benson, O. O., and Strehler, A. F., in Handbook of Respiratory Physiology, ed. W. M. Boothby. Texas, USAF School of Aviation Medicine, 1954.

10 Wood, J. E., and Roy, S. B., American fournal of Medical Science, 1970 259, 56.

1 Weil, J. V., Byrne-Quinn, E., Battock, D. J., Grover, R. F., and Chidsey, C. A., Clinical Science, 1971, 40, 235.

12 Cross, K. W., in Handbook of Physiology, Section 3, vol. 2, ed. W. O. Fenn and H. Rahn. Washington, American Physiological Society, 1965.

13 Henney, R. P., Vasko, J. S., Brawley, R. K., Oldham, H. N., and Morrow, A. G., American Heart fournal, 1966, 72, 242.

\section{Puzzling Cases of Secondary Syphilis}

Before the days of specialization the great physicians recognized syphilis as a disease with such protean manifestations that its diagnosis of ten presented great difficulties. This was in particular true of early acquired syphilis in the secondary stage of the disease, when over 80 other diseases had to be considered in the differential diagnosis from its many and various clinical forms. Nowadays it is true that only about $2 \%$ out of all cases seen in the special clinics are due to syphilis in all stages, but even so over 1,000 new cases of early infectious syphilis were reported in 1970. It is probable that a large number of other cases remained undiagnosed or were misdiagnosed in general and specialist practice in the same year.

Britain is fortunate in having a highly organized venereal disease service, with consultants specializing in the subject and contributing to the teaching of undergraduate and postgraduate students. They are able to emphasize to doctors in training the importance of appreciating that patients with early syphilis in the secondary stage rarely present directly to the special clinics. The main symptoms of lassitude, anorexia, headache, sore throat, hoarseness, and arthralgia are common to many other organic or functional diseases. A general practitioner may note that he is dealing with an inflammatory condition by finding pyrexia and anaemia associated with a raised erythrocyte sedimentation rate, but the common signs of rashes, mucosal and perianal lesions, and general adenopathy may persuade him to refer the patient to a dermatologist, an otolaryngologist, a proctologist, or a general physician. There are also a small percentage of cases with rarer secondary lesions of the meninges, the uveal tract of the eye, the viscera, and the bones, which may bring the patient to a neurologist, an ophthalmologist, a gastroenterologist, or an orthopaedic surgeon.

A recent paper by J. D. J. Parker ${ }^{1}$ is of particular interest in this respect, as he was able to report one case of each of these four rare manifestations of the secondary stage seen in a special clinic. Case 1 was of a 43 -year-old homosexual male admitted deeply jaundiced. Liver biopsy showed slight cellular infiltration with round cells, plasma cells, and fibroblasts. The erythrocyte sedimentation rate was $70 \mathrm{~mm}$ in one hour. The diagnosis was in doubt until two weeks later he was noted to have a generalized rash, with involvement of palms and soles, and general adenopathy. Serological tests were positive. Routine treatment with penicillin resulted in resolution of his jaundice and reversal of these reactions. No other cause for the jaundice could be suggested. Case 2 was of a 35-year-old bisexual male who had been treated for early syphilis in the primary stage at another clinic the previous year and had developed penicillin hypersensitivity. He attended a medical outpatients department with a tender swelling below his left tibial tuberosity. An $x$-ray showed periostitis. He was referred to the special clinic, where serological tests were found to be positive. The patient was admitted for treatment with a 14-day course of cephaloridine in view of the penicillin allergy, and the symptoms improved. $X$-ray examination three months later showed that his periostitis had resolved, and after one year the reagin titre had fallen to 1 in 2. Case 3 was of a widow aged 47 who attended an eye hospital with anterior uveitis, and a generalized rash was noted. As a result she was referred to the skin department. Serological tests for syphilis were found to be positive, and so she was sent on to the special clinic, where the additional history of two months' arthralgia was noted and papilloedema observed. A course of penicillin was given. Eight weeks later the uveitis had resolved, and the reagin titre had been reduced to 1 in 2 . The fourth case was of a married man aged 39 who complained of deafness and was seen in an E.N.T. department. He then attended the special clinic because he was worried about a recent sex risk. He also complained of arthralgia of six weeks' duration. The E.S.R. was $42 \mathrm{~mm}$ in one hour and the serological tests were positive. There was now a perceptive deafness, more marked on the right side, and papilloedema and a generalized rash. Treponema pallidum was found by dark-ground examination from a split papule at the angle of the mouth. Examination of his spinal fluid showed 173 
lymphocytes per $\mathrm{mm}^{3}$, protein of $43 \mathrm{mg} / 100 \mathrm{ml}$. The Wassermann reaction was positive and the Lange colloidal gold curve showed a "mid-zone" reaction. He was given a course of penicillin for 20 days. The cerebrospinal fluid had returned to normal six months later and there was some improvement in his hearing; the blood reagin tests were negative within 20 months.

These cases illustrate the importance of adequate undergraduate teaching by experts on the subject of the venereal diseases if doctors in practice are to be fully equipped to diagnose it despite its deceptive appearance in many cases.

1 Parker, J. D. J., British fournal of Venereal Diseases, 1972, 48, 32.

\section{Platelet Embolism}

Emboli of cardiac origin, by occluding either the cerebral or carotid arteries, are a common cause of cerebral infarction. ${ }^{1} 2$ These emboli are due to a variety of cardiac lesions, the commonest being rheumatic and anterio-sclerotic diseases, especially when associated with cardiac dysrhythmia.

Strokes so caused were found to have been ushered in by seizures in $40 \%$ of a recently published series. ${ }^{3}$ Other workers have also reported a high incidence of seizures in cerebral embolism. ${ }^{4}$ As a result of increasing tendency to resort to cardiac valve replacements by prosthesis, this is now a common source of cerebral embolism. ${ }^{3}$ Two types of emboli from prosthetic replacements were recognized. Large emboli believed to be due to dislodged fragments of red thrombus from the cage of the artificial valve or its seating in the myocardium most commonly arise during the immediate postoperative period. Smaller emboli, fibrinoplatelet in nature, are liable to arise three to five years after insertion of the prosthesis, especially of a ball valve fabricated from Silastic material. A double-blind study suggests that the frequency of this type of embolism can be lowered by combining the customary anticoagulant therapy with dipyridamole $400 \mathrm{mg}$ daily. 5 Platelet emboli can produce cerebral and retinal lesions, and a fundus photograph from a case of aortic prosthesis shows a typical cotton-wool spot lesion in every way similar to that produced by experimental embolization of retinal arterioles by means of small glass spheres. 6 In view of the widely held view that platelet embolism plays an important part in the causation of unilateral amaurosis fugax, it is noteworthy that this phenomenon was not mentioned among the thromboembolic complications following cardiac valve replacement in these two large series.

Platelet aggregates have been shown to be of two typesnamely, irreversible and reversible. ${ }^{7}$ The platelet aggregates seen during attacks of amaurosis fugax as "white bodies" in retinal arteries, in association with segmentation of blood column in retinal veins, are probably of the latter type. These retinal circulatory phenomena provide the basis for the embolic theory of unilateral amaurosis fugax..$^{8-12}$

In the normal circulation the formed elements of the blood remain discrete and showing no tendency to adhere to each other. Using a technique which renders possible in vivo microscopy of the retinal vessels in experimental animals, K. Thuranszky ${ }^{13}$ has obtained photographs to show that the suspension stability of the blood elements judged by segmentation of blood column is quantitatively related to perfusion pressure. Normal platelets are capable of adhering to each other (aggregation) and to foreign surfaces such as glass (adhesion). These two properties appear to be identical, since in the so-called Glanzmann-Naegeli type of inherited thrombasthenia the platelets fail to clump and also do not adhere. There is now evidence that platelet adhesiveness, and therefore clumping, becomes greatly increased under conditions of reduced blood flow. ${ }^{14}$ The retinal intravascular phenomena observed during attacks of unilateral amaurosis can therefore be regarded as resulting from a fall in perfusion pressure. Ischaemia causes blindness, and diminished velocity of blood flow leads to varying degrees of fragmentation of the blood column in some retinal vessels, as also to clumping of platelets. The opposing intraocular pressure is an important factor in magnifying the effect of the fall of perfusion pressure on the retinal circulation. ${ }^{15}$ Blood flow may cease entirely and arteries become empty of blood or "white bodies," and individual segments of intravascular blood columns may show varying degrees of to-and-fro or centrifugal movements. E. M. Fisher has concluded that "symptomatic retinal ischaemia" can, however, occur in the absence of these ophthalmoscopic abnormalities "merely as a result of slowing of the blood flow". 8 The facility with which segmentation of the blood column occurs when velocity of blood flow is reduced, is related to the sedimentation rate.1617 Unilateral amaurosis fugax can therefore be regarded as a variant of a "transient stroke" of the type discussed in these columns recently. ${ }^{18}$ The concept that unilateral amaurosis fugax was due to transient fall of carotid perfusion pressure was, according to $\mathrm{H}$. P. Wagener, first formulated in 1951.19-21 It accounts for cases in which ipsilateral blindness appears suddenly some days after surgical constriction of one carotid artery, and can be promptly relieved by release of the artery. It also explains a rare but well-documented syndrome in which unilateral amaurosis can be provoked at will by a stereotyped manoeuvre. ${ }^{22}$

E. G. Loring was among the first to question the validity of embolism as a cause of unilateral amaurosis fugax. He wrote nearly a century ago: "If it were embolism how could it be possible that precisely similar attacks had occurred over and over again. It would certainly seem to pass belief that such a thing could occur over and over again for the space of 25 years". 23 Fisher, though accepting platelet embolism as cause of this syndrome, voiced his misgivings in almost similar terms: "That a kind of secondary microembolism could cause the same clinical picture on more than 700 occasions tests the imagination".8

\footnotetext{
1 Blackwood, W., Hallpike, J. F., Kocen, R. S., and Mair, W. G. P., Brain, $1969,92,897$

Castaigne, P., Lhermitte, F., Gautier, J. C., Escourolle, R., and Derouesné, C., Brain, 1970, 93, 231.

Meyer, J. S., Charney, J. Z., Rivera, V. M., and Mathew, N. T., Stroke, $1971,2,541$.

- Patrick, J., and Whitty, C. W. M., Lancet, 1965, 1, 1291.

S Sullivan, J. M., Harken, D. E., and Gorlin, R., New England Fournal of Medicine, 1971, 284, 1391

- British Medical fournal, 1966, 2, 1474

7 Macmillan, D. C., Nature, 1966, 211, 140.

8 Fisher, E. M., Neurology, 1959, 9, 333

- Russell, R. R., Lancet, 1961, 2, 1422

10 Ashley, M., Oakley, N., Lorentz, I., and Scott, D., British Medical Fournal, 1963, 2, 894.

11 McBrien, D. J., Bradley, R. D., and Ashton, N., Lancet, 1963, 1, 697.

12 Gerstenfeld, J., American Fournal of Ophthalmology, 1964, 58, 198.

18 Thuranszky, K., Der Blutkreislauf der Netzhaut. Ungarischen Akademie der Wissenschaften, Budapest, 1957.

4 Fitzgerald, D. E., Butterfield, W. J. H., Smink, D., and Kruisheer, H. E. J., Atherosclerosis, 1971, 13, 217.

15 Behrman, S., Postgraduate Medical fournal, 1954, 30, 570.

16 Snow, P. J. D., Lancet, 1957, 1, 65.
17 Johnson, W. A., and Kearns, T. P., American fournal of Ophthalmology, 1962, 54, 201 .

18 British Medical fournal, 1971, 3, 723.

19 Wagener, H. P., Illinois Medical fournal, 1957, 111, 21

20 Behrman, S., Archives of Ophthalmology, 1951, 45, 458.

21 Fisher, M., Archives of Neurology and Psychiatry, 1951, 65, 346.

28 Sanders, T. E., American fournal of Ophthalmology, 1939, 22, 861

23 Loring, E. G., American Fournal of Medical Sciences, 1874, 67, 313
} 